Article

\title{
Fine-Scale Spatiotemporal Analysis of Population Vulnerability to Earthquake Disasters: Theoretical Models and Application to Cities
}

\author{
Haihong Yuan ${ }^{1, *(\mathbb{D}}$, Xiaolu Gao ${ }^{2}$ and Wei $\mathrm{Qi}^{2}$ \\ 1 Department of Geography \& Spatial Information Techniques, Ningbo University-University of Angers, Joint \\ Institute at Ningbo, Ningbo University, Ningbo 315211, China \\ 2 Key Laboratory of Regional Sustainable Development Modeling, Institute of Geographic Sciences and \\ Natural Resources Research, Chinese Academy of Sciences, Beijing 100101, China; gaoxl@igsnrr.ac.cn (X.G.); \\ cc7v@163.com (W.Q.) \\ * Correspondence: haihongyuan321@126.com
}

Received: 13 February 2019; Accepted: 8 April 2019; Published: 11 April 2019

check for updates

\begin{abstract}
China is particularly vulnerable to earthquakes and has suffered a high number of earthquake casualties. Therefore, it is imperative to develop effective methods for assessing population vulnerability in order to provide practical and useful information for pre-disaster preparedness and emergency management. However, there are many problems with existing approaches to assessing population vulnerability in China. This study developed a method combining dasymetric population mapping with population vulnerability indexing to estimate populations' vulnerability to earthquakes at block level in daytime and nighttime. The method aims to provide high spatial-temporal resolution information on vulnerable populations and population vulnerability. In a case study of Haidian District in Beijing, we combined our population spatialization model with a population vulnerability assessment model and sensitivity analysis to efficiently identify areas with high population vulnerability, the location of vulnerable populations, and key sensitive factors influencing population vulnerability during daytime and nighttime. This information can be used to identify where and which aspects of pre-disaster mitigation, preparedness, and emergency response activities should be prioritized. It is expected that these methods will be used to analyze vulnerable populations and population vulnerability in other areas of China.
\end{abstract}

Keywords: population vulnerability; assessment methodology; fine-scale; spatiotemporal analysis; Haidian District of Beijing

\section{Introduction}

Earthquakes are among the world's deadliest natural hazards. When occurring in densely populated and poorly planned earthquake-prone regions, earthquakes can have devastating consequences. Like other developing countries, China is especially vulnerable to earthquakes and has suffered a high number of casualties [1]. In the past decade, the deadliest earthquake was the 2008 Wenchuan earthquake (magnitude 7.9; 69,227 deaths and 17,923 missing) [2]. Many Chinese cities still face a high earthquake disaster risk. This is mainly due to three factors: the complex and vulnerable socioeconomic system that has developed alongside rapid urbanization and socioeconomic transformation [3], highly centralized population and wealth in cities [3,4], and inadequate infrastructure [5]. Furthermore, 22 provincial capital cities and about two-thirds of large cities (i.e., over one million residents) are located in high seismic zones, with intensities higher than VII on the China Seismic Intensity Scale ("Liedu" in Chinese) [6,7]. 
Since earthquakes cannot be prevented, all effective measures should be applied, especially those reducing exposed populations' vulnerability, which is recognized as a core element of managing or reducing disaster risks [8,9]. There is great value in quantifying and spatially mapping a population's social vulnerability and identifying the key factors influencing high social vulnerability, enabling mitigation and adaptation strategies to target areas with the most vulnerable populations [10].

Though many definitions of social vulnerability have been proposed over the last two decades, the literature still lacks a comprehensive definition to meet the requirements of various disciplines [11]. The definitions differ across fields and for different spatial levels, mostly due to the multifaceted and scalar-dependent character of social vulnerability [12]. Most definitions treat vulnerability as a function of susceptibility to loss and of recovery capacity, or "resilience" [13]. In this paper, we define population vulnerability as a population's susceptibility to harm when exposed to disasters.

Many studies of social vulnerability have been conducted, and a variety of indicators and approaches at different spatial scales have been proposed, including the national level [14], urban level [15], sub-district level [8], community level [16], parcel level [17], different census levels [10,18], household level [19], and even the individual level [20]. Overall, social vulnerability comprises individual and collective aspects that differ in their indicators and scales. Collective vulnerability is often analyzed at community, regional, or national scale, while individual vulnerability is connected to the household and individual scales [21].

Studies suggest that vulnerability is dynamic, which means that it varies with spatial and time scale [13]. The accuracy of social vulnerability assessment depends on the accuracy of input data. This highlights the importance of fine-scale data for accurately estimating social vulnerability. In many developed countries, exposure data for social vulnerability assessment are available at the fine-scale level; in China, however, such data are often only available at the administrative unit level [22,23]. Administrative areal units are usually over-aggregated [24]. Therefore, most studies of social vulnerability in China have used highly aggregated spatial units such as towns and subdistricts [25], districts [26], counties and prefectures [27], and provinces [28]; very few have been conducted at the community [29] or household scale [30]. Macro-scale analyses typically sacrifice detail for common patterns and potentially fail to detect the heterogeneity of vulnerability at smaller scales [19]. The smallest administrative unit in China is the sub-district, yet even the sub-district scale is too coarse to identify spatial variations in population vulnerability.

Population vulnerability is also associated with temporal variations: the spatial distribution and density of population is strongly time dependent, due to different population trajectories during daytime and nighttime (e.g., daytime working population, commuting population, nighttime residential population), especially in metropolitan areas [31]. Therefore, to estimate population exposure and assess population vulnerability at appropriate temporal and spatial scales, it is necessary to move beyond official statistics. Fine-scale exposure data are not usually available in China due to confidentiality or the absence of statistical data. This study develops a method combining dasymetric population mapping with vulnerability indexing to estimate population vulnerability at block level in daytime and nighttime, accounting for fine-scale spatial and temporal variability.

\section{Research Design and Methodology}

Consensus remains lacking on what should and should not be included in vulnerability assessment, and different evaluation models have been used by researchers, planners, and disaster managers [32]. Composite indicators have been most commonly employed [15], including the Social Vulnerability Index [33], the Prevalent Vulnerability Index [34], Environmental Sustainability Index [35], and Human Development Index [36]. Social vulnerability indicators are powerful tools as they summarize complexity and provide quantitative metrics to compare places [15].

We employed the following three-step process to construct a block-level population vulnerability index and conduct assessment and sensitivity analyses of population vulnerability. 
First, we defined the conceptual framework and index structure, adopting a hierarchical design. We then identified the relevant sub-indices, indicators, and variables of the population vulnerability index. In the weighting and aggregation stage, a questionnaire evaluation method was employed to derive differential variable weights, before aggregating the weighted normalized indicators to form the index.

Second, we developed a population spatialization model to obtain data on the population vulnerability indicators. Dasymetric mapping techniques were used to disaggregate total population from administrative area level to blocks.

Third, we conducted sensitivity analysis to determine a sensitivity score for each indicator, identified the key factors influencing population vulnerability, and then drew sensitivity distribution maps.

\subsection{Construction of Block-level Population Vulnerability Index}

Developing a population vulnerability index involves sequential and multi-stage processes, including structural design, choice of analysis scale, selection of indicators, data transformation, scaling, weighting, and aggregation.

\subsubsection{Structure Design}

A vulnerability index can be structured with a deductive, hierarchical, or inductive design [37]. We chose a hierarchical design, aggregating indicators into sub-indices that share the same underlying dimension of vulnerability.

\subsubsection{Choice of Analysis Scale}

The block is a spatial entity enclosed by roads [38]. Urban structure types can be defined as spatial units on a block scale that are homogeneous in terms of physical appearance (land cover), usage (land use), and approximate age [39]. The block unit is important for not only contemporary urban planning and design and urban studies but also land administration [40]. Building vulnerability is a principal factor affecting earthquake casualties [41], and the block scale is particularly suitable for analyzing the building inventory and thus assessing its vulnerability to disasters [39]. Therefore, assessing population vulnerability at the block scale can provide practical and useful information for pre-disaster preparedness, emergency management, and spatial planning. This study uses city blocks as the basic unit of analysis. In ArcGIS, a total of 647 blocks were generated as units for evaluation.

\subsubsection{Selection of Indicators}

The number and type of indicators used in constructing a social vulnerability index vary considerably depending on the type of analysis and methods used [17]. Social vulnerability is most often described in terms of the characteristics of people [33], but it also includes those characteristics of communities, government policy, public resources, etc. that reflect place inequalities potentially manifesting at macro scale but not at a fine scale, such as block level. Spatial scale should be considered when identifying social vulnerability factors, as some only manifest at certain scales [13].

Cutter et al. [42] note that some broad indicators repeatedly appear in social vulnerability analyses, although different proxies or variables may be used to represent them. The characteristics most often found in the literature include socioeconomic status (wealth or poverty), special needs, age, gender, employment, occupation, education, access to medical services, population growth, housing tenure (ownership), social dependence, and race and ethnicity. Cutter et al. [42] also note the importance of considering not only the proportion of residents thus broadly characterized but also how each factor or variable interacts to produce socially vulnerable populations. We found few studies focusing on these issues at a fine scale.

Based on the above analysis, this study focuses on the population characteristics and structure influencing social vulnerability, aiming to identify the distribution of socially vulnerable populations 
and conduct a fine-scale study of population vulnerability, thus neglecting larger-scale factors of social vulnerability. Our vulnerability index covers almost all the characteristics most often found in the literature, as identified by Cutter et al. [42], but some indicators were changed due to the particularity of China's urbanization. For example, whereas race and ethnicity are important factors influencing social vulnerability at a fine-scale in many developed countries, China's society is Han-dominated, especially in Beijing. China also differs from most developed countries in that most of its rural-to-urban migrants are workers without equal access to public services. Accordingly, we consider the floating population as a vulnerable population.

Population density, gender discrimination, socioeconomic status, and public health conditions are widely considered the most important causes of vulnerability for individuals exposed to disasters and emergencies [11]. Socially vulnerable groups are victims who tend to have special needs or already face drawbacks, such as children, the elderly, people with disabilities, those living in poverty, and migrants. These people experience higher levels of social vulnerability [43,44].

This study evaluates population vulnerability at a fine scale based on population attributes and population spatial characteristics, and determines the elements of population vulnerability with respect to three aspects: the natural, socioeconomic, and spatial attributes of a population. The natural attributes of population vulnerability are the different physiological characteristics that affect individuals' ability to respond to disasters. Children, the elderly, people with disabilities, hospital patients, and school dormitory residents are more likely to be vulnerable to disasters [11,45]. Historical analysis of earthquake casualties in China indicates that casualty numbers are closely related to these physiological characteristics of the affected population [46]. The socioeconomic attributes of population vulnerability include various factors, such as the affected population's socioeconomic status and education level, which explain differences in disaster exposure, level of earthquake awareness, pre-disaster prevention, escape from disaster, and ability to recover and rebuild after a disaster. For example, individuals with a low education level (especially illiterates) often lack knowledge of earthquake disasters and how to respond to them, leaving them less prepared for and able to escape from earthquakes [27]. Poor people often live in less safe settlements and have restricted access to resources [9]. The spatial attribute of population vulnerability used in this study is the spatial agglomeration of a population. Areas with high population density have higher exposure to disaster, so casualties tend be higher [47], especially as they face greater evacuation difficulties [48]. In China, high population density reflects rapid urbanization, and it is difficult to satisfy residents' needs in a place undergoing rapid urban growth [13]. In total, 11 variables were selected to measure population vulnerability, as shown in Table 1.

Table 1. Population vulnerability indicators and related variables.

\begin{tabular}{|c|c|c|}
\hline Sub-Indices & Indicators & $\begin{array}{c}\text { Variables } \\
\text { (\% of Total Population) }\end{array}$ \\
\hline \multirow{5}{*}{ Natural characteristics } & Gender & Female \\
\hline & & Infant \\
\hline & Age & Kindergarten student \\
\hline & & Primary school student \\
\hline & Health condition & Hospital patient \\
\hline \multirow{3}{*}{ Socioeconomic characteristics } & Education level & $\begin{array}{c}\text { Education level of junior high school or } \\
\text { below }\end{array}$ \\
\hline & Employment status & Unemployed \\
\hline & Mobility & Floating population \\
\hline Spatial characteristic & Degree of population agglomeration & Population density \\
\hline
\end{tabular}

\subsubsection{Normalization of Variables}

Normalization is performed to use a common and dimensionless scale for all indicators. As min-max linear scaling is most often used for hierarchical designs [37], we adopt it in this study. 


\subsubsection{Weighting}

Social vulnerability indexes typically suffer from methodological weaknesses regarding indicator weighting and aggregation [42]. Various statistical and expert approaches have been used to obtain indicator weights, but by far the most frequently used approach is equal weighting [37], which is typically employed due to the lack of reliable theoretical or statistical evidence for assigning weights, rather than to suggest that all indicators are equally important. This study uses unequal weighting based on the relative importance of each indicator in vulnerability assessment. The expert scoring method is widely used to weight social vulnerability indicators [21,49], and we adopted a version similar to that of Huynh and Stringer [21]. We distributed a total of 120 questionnaires to government staff and experts in university departments and research institutes, asking them to directly score the influence of each indicator on population vulnerability on a seven-point scale (7: extremely large impact; 5: very large impact; 3: large impact; 1 : general impact). A total of 111 valid questionnaires were returned, representing a response rate of $92.5 \%$. Each indicator's importance score was converted to a weight according to the following formula: indicator weight $=$ impact score of indicator $\div$ total impact score of all indicators. Table 2 reports the weight of each indicator of population vulnerability.

Table 2. Weight of each indicator of population vulnerability.

\begin{tabular}{cc}
\hline Variables (\% of Total Population) & Weighting (0-1) \\
Female & 0.12 \\
Elderly & 0.13 \\
Infant & 0.14 \\
Kindergarten student & 0.11 \\
Primary school student & 0.07 \\
Middle school student & 0.07 \\
Hospital patient & 0.11 \\
Education level of junior high school or below & 0.06 \\
Unemployed & 0.07 \\
Floating population & 0.05 \\
Population density & 0.09 \\
\hline
\end{tabular}

\subsubsection{Aggregation}

Taking into account all indicators and their relative weights (Table 2), the population vulnerability index of each block is calculated as follows:

$$
M_{i}=\frac{\sum_{i=1}^{n}\left(Y_{i j} \times K_{j}\right)}{\sum K_{j}}
$$

where $M_{i}$ is the population vulnerability index of the $i$ th block; $K_{j}$ is the weight of the $j$ th variable; and $Y_{i j}$ is the normalized value of the $j$ th population vulnerability variable in the $i$ th block.

GIS was employed to visualize the distinct population vulnerability levels of the aforementioned 647 blocks.

\subsection{Population Spatialization Model}

To obtain data on the indicators in Table 1 at block scale, we needed to develop a population spatialization model. Different spatialization models of population data are used around the world, including multi-source information fusion [50], dasymetric mapping [51,52], and multiple regression methods [53], and many related models have been developed. Dong et al. [54] comprehensively analyze and compare these models and identify their respective advantages and limitations. Dasymetric mapping techniques are suitable for the fine-scale spatialization of population in urban areas. Scholars have detailedly reviewed dasymetric mapping techniques and proposed new techniques 
for the fine-scale spatialization of urban populations [51,55]. The assumption of intra-unit or intra-land-use class homogeneity gives rise to the modifiable areal unit problem (MAUP) for most dasymetric mapping techniques. There are also problems with detection accuracy when using fine-spatial-resolution remote sensing for small-area population estimation, necessitating improvement in building extraction and land-use classification methods and reduction in the bias of building attributes estimation [56]. Lwin and Murayama developed a GIS approach for estimating building population using census tract and building footprint data; however, their method overlooked temporal variation [57].

This study seeks to increase the spatial and temporal accuracy of dasymetric mapping. Our population spatialization model was designed to disaggregate total population counts from the sub-district level to the block level, primarily using building (Figure 1) and detailed land-use data. Sub-district ("jiedao," "xiang," and "zhen" in Chinese) is the smallest administrative unit in China. Population data at the sub-district level is, therefore, a prerequisite for obtaining a fine-scale population spatial database in China [54]. Land-use (or land-cover) data are closely associated with population density and so are used as important ancillary data to calculate population density in dasymetric mapping approaches. Detailed information on 13 types of urban land use was used in this study. As each land-use class has a characteristic population density, we seek to recognize the difference in population density between land-use classes. Intra-land-use class variation in population density variation, which can be caused by detached housing, multiple-unit housing, or unpopulated spaces [55], was identified using individual building-level data. Openshaw [58] identifies the following sources of error in micro-spatial analysis: the positioning of objects; the attributes associated with objects; the modeling of spatial variation (e.g., by assuming spatial homogeneity between objects). Fine-scale population distribution analysis at the building level can greatly reduce errors from all three sources, since we know the exact position and attributes (e.g., footprint area, number of floors, and use type) of individual buildings. The aggregation of individual building-level data can greatly reduce spatial aggregation error and mitigate the impact of the MAUP. Building blocks constitute meaningful reference units for the disaggregated population, as they reflect real-world housing patterns (e.g., highand low-rise buildings) and population distributions [55].

In sum, this study extends our earlier model [8] by building the relational model of vulnerable population-time (day and night)-land use (See Table 3). We disaggregated the sub-district population data down to building level for 13 land use types, and then reaggregated up to the block unit using the dasymetric mapping technique we developed. Detailed information on the population spatialization model can be found in our earlier study [8]. Our methods significantly reduce the impact of the MAUP, while high-precision building and detailed land-use data improve the spatial and temporal accuracy of block-level population data. 


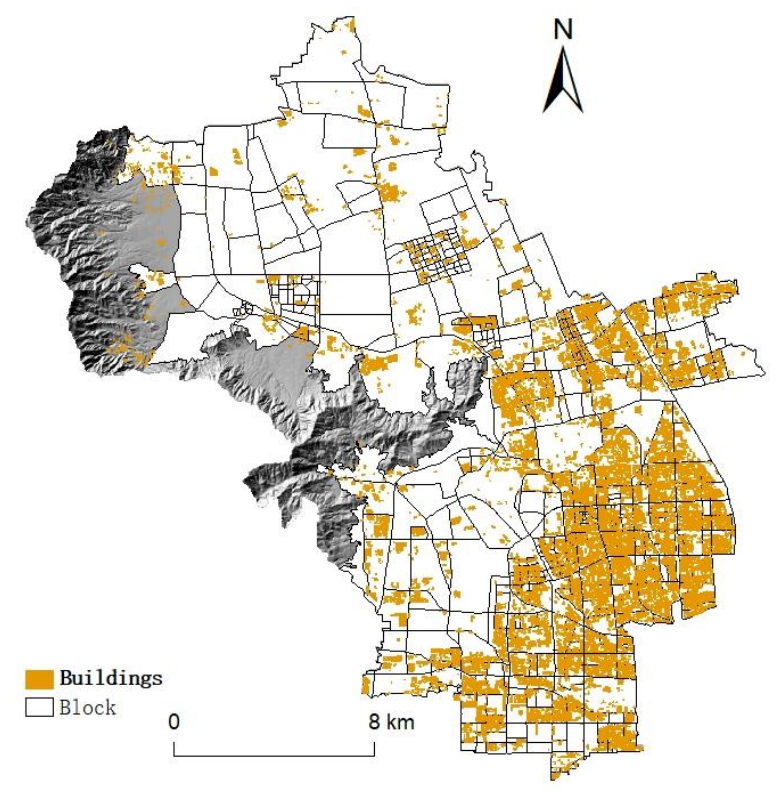

Figure 1. Spatial distribution of different building types in Haidian District.

Table 3. The relational model of vulnerable population-time (day and night)-land use.

\begin{tabular}{ccc}
\hline \multirow{2}{*}{ Vulnerable Groups } & \multicolumn{2}{c}{ Spatiotemporal Distribution of Human Population } \\
\cline { 2 - 3 } & Day (D) & Night (N) \\
\hline Elderly & Urban and township residential land (I8) & Urban and township residential land (I8) \\
Infant (0-3 years old) & Urban and township residential land (I8) & Urban and township residential land (I8) \\
Kindergarten student & Kindergarten (I4) & Urban and township residential land (I8) \\
Primary school student & Primary school (I5) & Urban and township residential land (I8) \\
Middle school student & Middle school (I6) & Urban and township residential land (I8) \\
Floating population & Industrial land (I1-I3) & Urban and township residential land (I8) \\
Hospital patient & Hospital (I12) & Urban and township residential land (I8) + \\
Education level of junior high & & \\
school or below & Industrial land (I1-I3) & Urban and township residential land (I8) \\
Unemployed & Urban and township residential land (I8) & Urban and township residential land (I8) \\
Female & Industrial land (I1-13) & Urban and township residential land (I8) \\
\hline
\end{tabular}

Note: I1-I13 represent the types of urban land use; for details, see our earlier study [8].

\subsection{Sensitivity Analysis of Population Vulnerability}

The sensitivity analysis assumes that the model is expressed as $y=f\left(x_{1}, x_{2}, x_{3} \ldots, x_{n}\right)$, where $\mathrm{x}_{i}$ is the $i$ th attribute value of the model, and each attribute varies within a possible range of values. It predicts the influence of changes in these attributes on the output value of the model, and each attribute's degree of influence becomes its sensitivity coefficient. With some modifications to the method used by Zhang and Huang [49] for sensitivity analysis of social vulnerability, the process in our study is as follows:

(1) The target influencing factor's weight is multiplied by 2 (as a randomly selected coefficient that should be larger than 1) while holding constant the weights of other influencing factors.

(2) To ensure that the sum of the 11 influencing factors' weights still equals 1 , and that, proportionally, the other 10 factors' weights are relatively constant, we adjust the weights of the other 10 influencing factors as follows:

$$
X_{n i}=\frac{X_{o i}\left(1-c X_{t j}\right)}{1-X_{t j}} \quad \mathrm{i}=1 \text { to } 11, \mathrm{j}=1 \text { to } 11
$$


where $X_{n i}$ is the new weight of $i$ th influencing factor; $X_{o i}$ is the original weight of $i$ th influencing factor; $X_{t j}$ is the original weight of the $j$ th target influencing factor; and $C$ is the coefficient ( 2 in this study).

(3) The new population vulnerability can be obtained from Eq. (1) using the new weights of the 11 influencing factors. The sensitivity score (Sens) is:

$$
\text { Sens }=\frac{V_{\text {new }}}{V_{\text {old }}}
$$

where $V_{\text {old }}$ is the vulnerability value before sensitivity analysis, and $V_{\text {new }}$ is the new value of population vulnerability. The higher the sensitivity score, the greater the influence of the target influencing factor.

Sensitivity analysis of block-scale population vulnerability is helpful for adopting more targeted remedial measures, and so will be especially significant in policy formulation and regional management.

\section{Application}

\subsection{Study area}

In 2017, Beijing had a permanent population of 21.7 million and a GDP of 2.8 trillion yuan. Beijing is at high risk of damaging earthquakes and most areas are located in a seismic zone with intensities higher than VII on the China Seismic Intensity Scale (as shown in Table 1 and Figure 2).

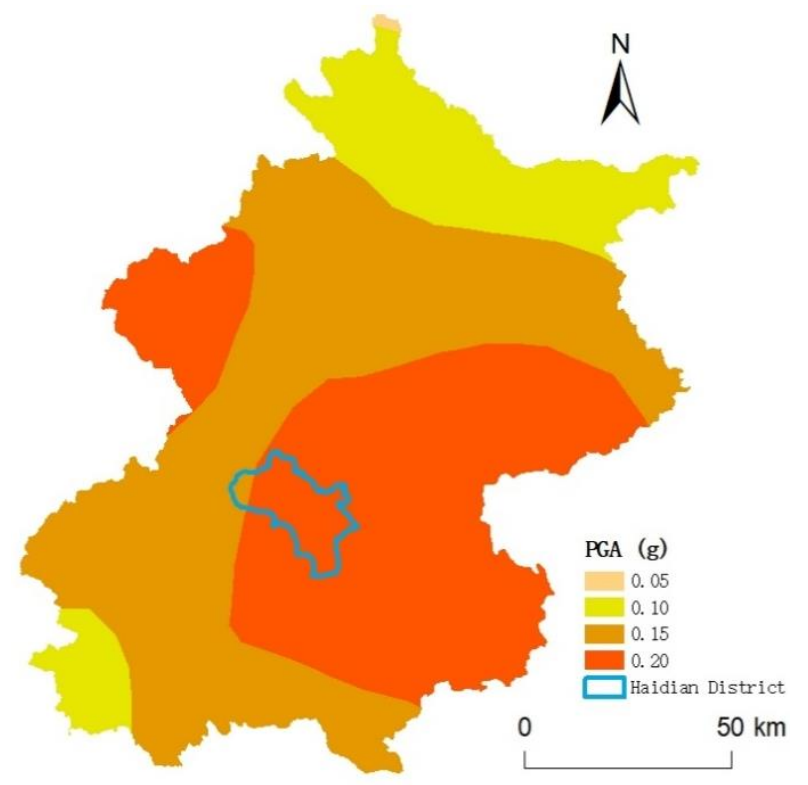

Figure 2. Peak ground acceleration map of Beijing and Haidian District.

We chose Haidian District to conduct a case study. Located toward the northwestern part of Beijing's urban core, Haidian District has an area of $430.8 \mathrm{~km}^{2}$ and, in 2017, had a permanent population of 3.48 million and an urbanization ratio of $98.45 \%$. Haidian District is the base of many universities and has become the center of China's IT industry. As shown in Figure 3, the district has 29 lower-level administrative units, called Jiedaos and Townships ("xiang" and "zhen"). 


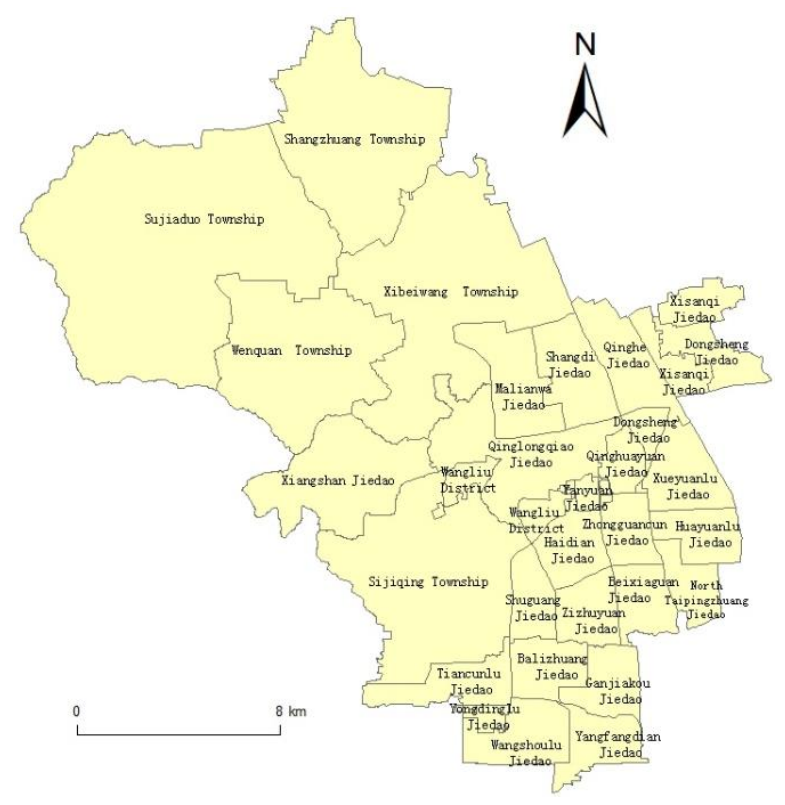

Figure 3. The administrative division of Haidian District, Beijing.

\subsection{Data and Processing}

The main problem with using census data is that they are only collected every 10 years in China; therefore, 2010 is the most recent year for which data are available.

The total population data for schools, hospitals, and tourism in Haidian District were obtained from the Beijing Statistical Yearbook 2011, the Beijing Haidian Statistical Yearbook 2011, and the Beijing Regional Statistical Yearbook 2011. Residential population data at sub-district level were derived from the $6^{\text {th }}$ National Census Data Bulletin of Beijing and the $6^{\text {th }}$ National Census Data Bulletin of Haidian District (both conducted in 2010). These data include both the local residential population and the floating population, but do not include the temporary population (those who have resided in the area for six months or less). The daily transient population, such as visitors, hotel guests, and hospital patients, was calculated by dividing the data in the statistical yearbooks by 365 . We calculated the total population at block level with the population spatialization model developed in our earlier study [8].

Spatial data were sourced from the Beijing Institute of Surveying and Mapping, including a 1:10,000 geographic information database that contained place names, administrative boundaries, etc., as well as 1:500 land-use data for Haidian District in 2010. These were used in conjunction with: (1) the Second National Land Survey of 2008; (2) 1:10,000 hospital and school vector data for 2011; and (3) 1:2,000 detailed building vector data for 2011. The building vector data showed the type, number of floors, construction date, and total area of each building.

\subsection{Pattern of Population Distribution During Daytime and Nighttime in Haidian District}

The population spatialization model was used to estimate the block-level population density, at daytime and nighttime, of the elderly, infants, women, kindergarten students, primary school students, middle school students, the floating population, hospital patients, those with an education level of junior high school or below, and the unemployed.

The total daytime and nighttime populations in Haidian District were 3.24 million and 3.3 million people, respectively. The daytime to nighttime population ratio was close to 1 , which reinforces Huang's conclusion [59]. The overall population density of Haidian District was $9923 / \mathrm{km}^{2}$ by day and $9428 / \mathrm{km}^{2}$ by night; however, the highest block-level population density at both daytime and nighttime is about $200,000 / \mathrm{km}^{2}$. Population density also varies significantly between daytime and nighttime (as shown in Figure 4, in which the shaded regions are mountainous areas). The blocks with high population density are concentrated in southern urban residential and service areas and the eastern 
high-tech parks. In the northwestern part of Haidian District, the population density is low in both daytime and nighttime because most of the area comprises sparsely populated mountains, farmland, and landscaped areas. We also obtained the block-scale distribution of vulnerable populations (e.g., women, elderly, and floating population), but only population density is reported and analyzed in this paper.

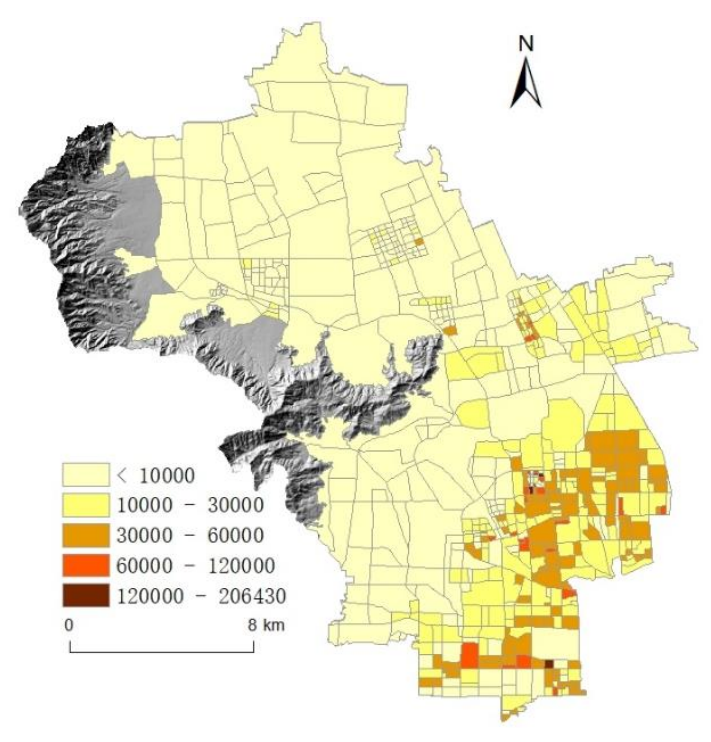

(a)

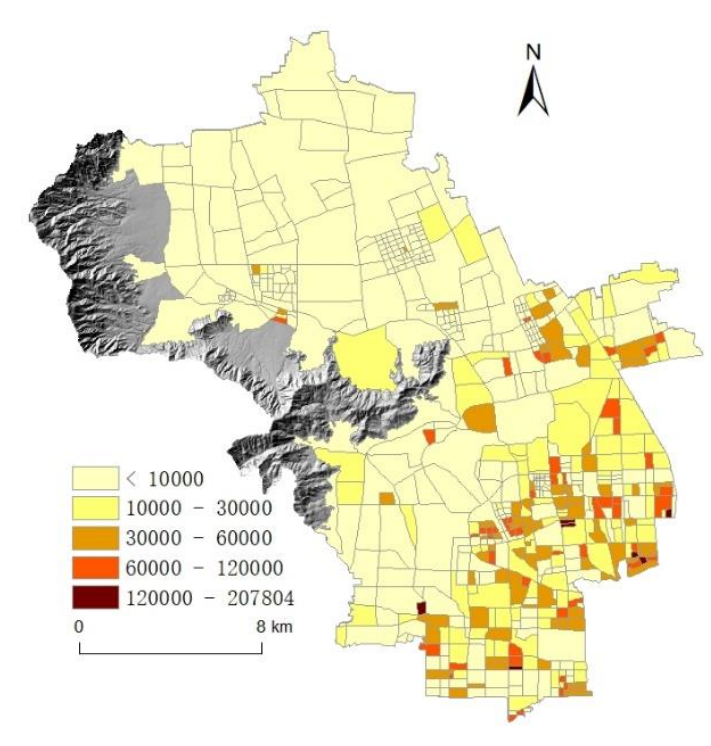

(b)

Figure 4. (a) Daytime population density block distribution; (b) Nighttime population density block distribution.

The government can improve pre-disaster mitigation, emergency management operations and implementation, and aid distribution with more precise information about the actual positions of susceptible populations [55]. Blocks with a large number of vulnerable people and high population density should be given higher priority in these disaster-related activities. For example, emergency officials can use a population density block distribution map to better recognize the small pockets of highly concentrated population requiring special attention.

\subsection{Assessment of Population Vulnerability During Daytime and Nighttime in Haidian District}

We estimated daytime and nighttime population vulnerability according to the population vulnerability index. Considering the distribution characteristics of population vulnerability, the standard deviation method was used to classify data values. The population vulnerability distribution maps are shown in Figure 5.

As Table 4 reports, 103 of 647 blocks (accounting for $23.6 \%$ of the total area of Haidian District) had high and very high levels of daytime population vulnerability. These blocks are concentrated in southern urban residential and service areas and the eastern high-tech parks. This distribution is primarily attributable to the many vulnerable populations (infants, primary and middle school students, and hospital patients) in southern urban residential and service areas, together with the daytime concentration of many people in central areas and industrial parks. The very high population density in these areas leads to high population vulnerability. The number and the area proportion of blocks with high and very high levels of population vulnerability at nighttime is relatively low compared to daytime. The main reason is that different kinds of vulnerable populations are more concentrated in residential land at night.

According to the land-use data of Haidian District and statistics in this paper, urban residential land, rural residential land, and university residences (where most of the population is distributed 
during nighttime) comprise about $30 \%$ of the district's total area, while secondary and tertiary industries (where most of the population is distributed during daytime) comprise about $60 \%$ thereof. Therefore, the overall population density on residential land at nighttime is higher than the overall population density on other types of land during daytime. The block-scale distributions of highly vulnerable areas indicate a tendency for these areas to shift north at night compared to daytime. This is mainly because vulnerable populations are distributed in residential areas at night, and many residential areas are in the downtown periphery.

In the event of an earthquake, the number of casualties in these blocks with high population vulnerability will be larger than in other blocks. This fine-scale data on population vulnerability can provide practical and accurate disaster information for emergency rescue, whereas information based on coarse administrative-level data may even delay and mislead decision-making during rescue [23].

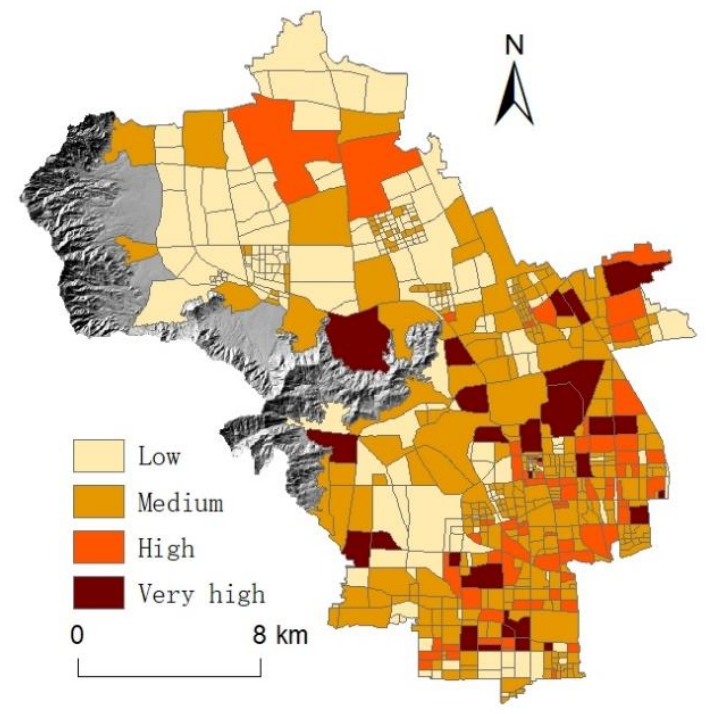

(a)

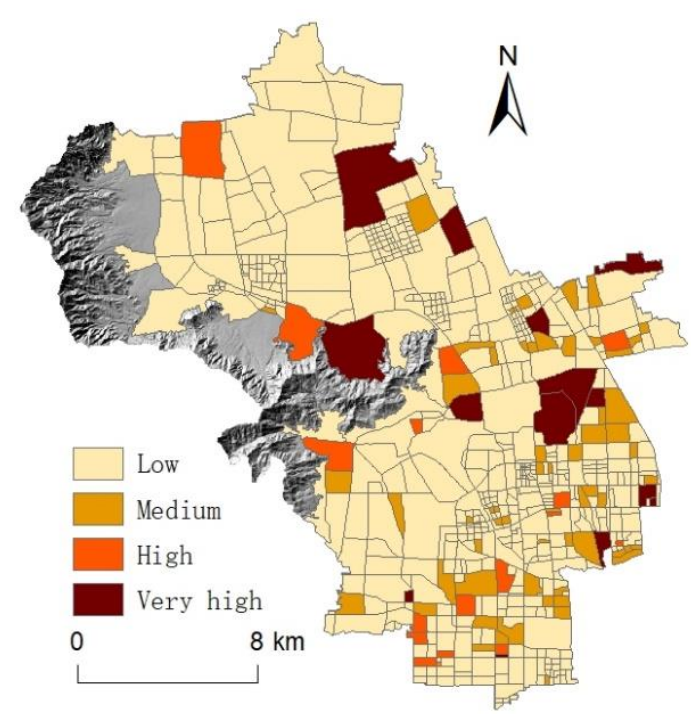

(b)

Figure 5. (a) Vulnerability level of blocks during daytime; (b) Vulnerability level of blocks at night.

Table 4. Statistics on the number and area of blocks at various levels of population vulnerability during daytime and nighttime.

\begin{tabular}{ccc}
\hline \multirow{2}{*}{ Vulnerability level } & Daytime & Nighttime \\
\cline { 2 - 3 } & Number of Blocks (Area Ratio) & Number of Blocks (Area Ratio) \\
\hline Low & $218(36.59 \%)$ & $554(79.45 \%)$ \\
Medium & $326(39.81 \%)$ & $64(7.93 \%)$ \\
High & $73(13.75 \%)$ & $16(4.61 \%)$ \\
Very high & $30(9.85 \%)$ & $13(8.01 \%)$ \\
\hline
\end{tabular}

\subsection{Sensitivity Analysis of Population Vulnerability During Daytime}

The 11 new weights for variables were then calculated, and a $647 \times 11$ data array was obtained, from which we derive the (maximum) sensitivity score of the 11 variables for each block, and then identify the (most) sensitive and disadvantageous influencing factors (Table 5).

The sensitivity analysis reveals that population density is the influencing factor to which the largest number of blocks are sensitive and most sensitive. High numbers of blocks are also found to be sensitive to the proportion of the floating population, females, people with an education level below junior high school, and the elderly. However, the number of blocks that are most sensitive to these factors is much lower than for population density, though relatively high numbers of blocks are most 
sensitive to the proportion of the elderly, females, and people with an education level below junior high school.

Table 5. Statistics of blocks sensitive to target influencing factors during daytime.

\begin{tabular}{ccc}
\hline Target Influencing Factors & $\begin{array}{c}\text { Number of Blocks Most Sensitive to } \\
\text { Target Influencing Factor }\end{array}$ & $\begin{array}{c}\text { Number of Blocks Sensitive to } \\
\text { Target Influencing Factor }\end{array}$ \\
\hline Population density & 186 & 340 \\
Proportion of elderly & 33 & 91 \\
Proportion of females & 28 & 125 \\
Proportion of population with & 24 & 126 \\
education level below junior high school & 18 & 67 \\
Proportion of infants & 15 & 103 \\
Proportion of floating population & 14 & 75 \\
Proportion of unemployed & 9 & 21 \\
Proportion of kindergarten students & 7 & 11 \\
Proportion of hospital patients & 2 & 19 \\
Proportion of middle school students & 1 & 56 \\
Proportion of primary school students & & \\
\hline
\end{tabular}

Sensitivity analysis identifies the sensitivity factors of blocks, which provide an effective starting point for reducing blocks' sensitivity and can potentially facilitate targeting disaster prevention and mitigation strategies. Although many factors can evidently affect population vulnerability, only typical sensitivity factors (population density and spatial distribution of the elderly) are reported and analyzed below.

Figure 6 identifies the blocks most sensitive, in terms of population vulnerability, to the elderly proportion. Given the need for special attention to the elderly, the government should prioritize measures to reduce population vulnerability in these blocks. Many blocks in Haidian District are sensitive to the elderly proportion, and coping strategies may also be proposed at regional level.

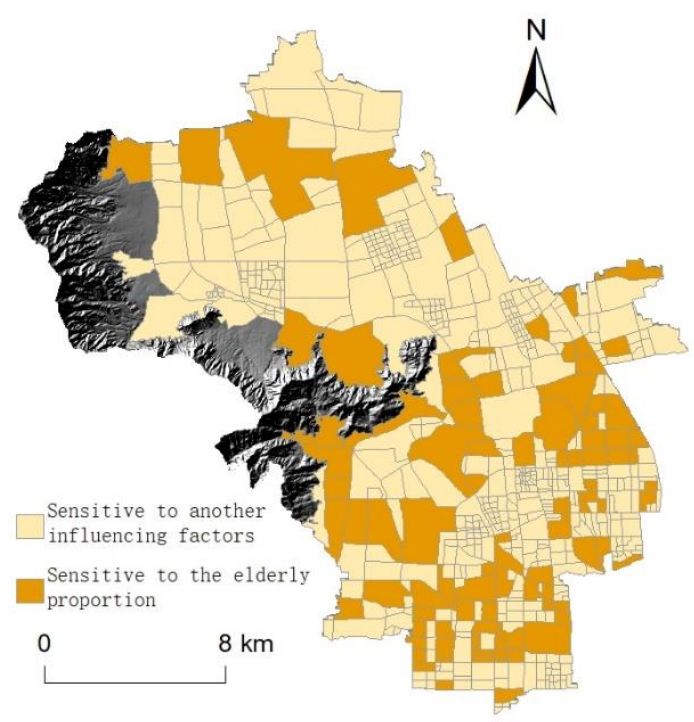

(a)

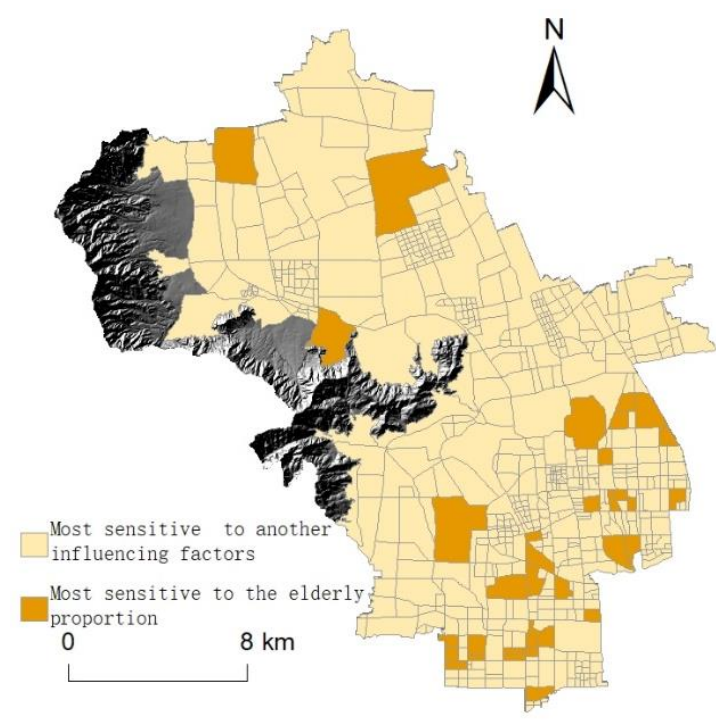

(b)

Figure 6. (a) Blocks sensitive to the elderly proportion during daytime; (b) Blocks most sensitive to the elderly proportion during daytime.

We conducted an overlay analysis with the jiedao layer and found that the blocks sensitive to the elderly proportion during daytime are concentrated in Xueyuanlu Jiedao, Sijiqing Town, Balizhuang Jiedao, Ganjiakou Jiedao, Shangzhuang Town, Wanshoulu Jiedao, and Qinghuayuan Jiedao. 
Meanwhile, the blocks most sensitive to the elderly proportion during daytime are concentrated in Xueyuanlu Jiedao, Balizhuang Jiedao, Wanshoulu Jiedao, and Zizhuyuan Jiedao.

Of the 11 influencing factors, population density has the highest sensitivity coefficient and affects the largest number of blocks. As shown in Figure 7, all the blocks that are sensitive or most sensitive to population density are small and mainly distributed in central Haidian. As the core area of the city, a large proportion of the population is densely distributed in these blocks. The high population density in city centers makes emergency planning for these urban spaces especially important, given the potential for casualties in a disaster. Accordingly, well-functioning evacuation routes should be maintained and adequate shelters provided for blocks with high population density in the central area $[60,61]$.

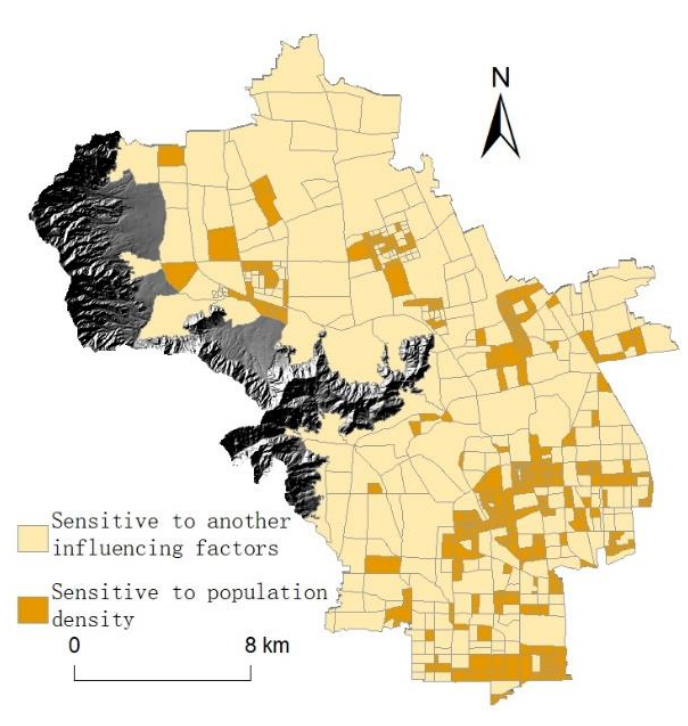

(a)

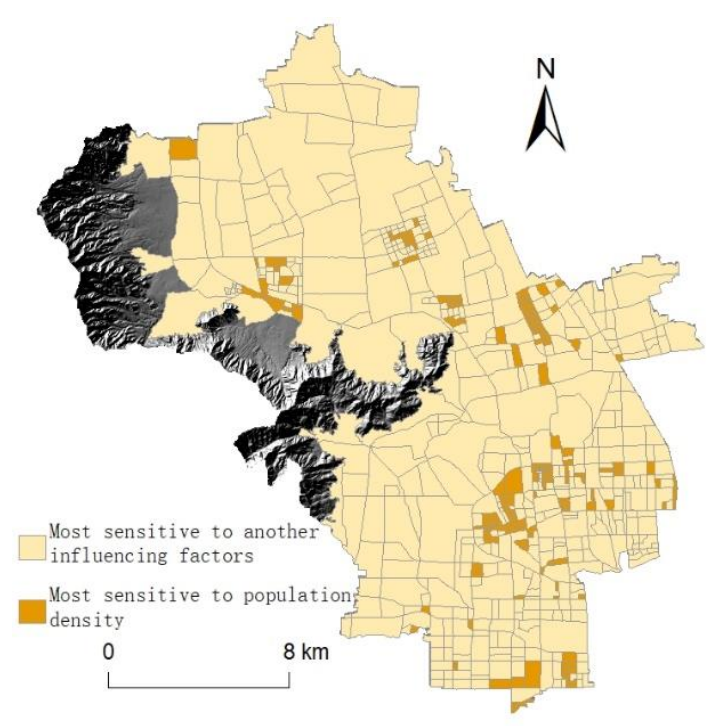

(b)

Figure 7. (a) Blocks sensitive to population density during daytime; (b) Blocks most sensitive to population density during daytime.

The blocks that are sensitive to daytime population density are concentrated in Haidian Jiedao, Zhongguancun Jiedao, Shangdi Jiedao, Shuguang Jiedao, Huayuanlu Jiedao, Zizhuyuan Jiedao, and Yangfangdian Jiedao. These blocks are spatially concentrated in southern urban residential and service areas and the eastern high-tech parks. Meanwhile, the blocks that are most sensitive to daytime population density are concentrated in Haidian Jiedao, Shangdi Jiedao, Zhongguancun Jiedao, Shuguang Jiedao, Huayuanlu Jiedao, Yangfangdian Jiedao, and Xibeiwang Town. These are mainly industrial agglomeration areas, hosting a dense distribution of many employed people during daytime.

\subsection{Sensitivity Analysis of Population Vulnerability at Night}

As reported in Table 6, the sensitivity analysis of population vulnerability at night shows insignificant changes in the major sensitive factors compared with those during daytime. As during daytime, although with comparatively less influence, population density is the influencing factor to which the largest number of blocks are sensitive and most sensitive. Compared to daytime, the spatial distribution of blocks that are sensitive and most sensitive to population density has changed. This is because the sensitive populations are more widely distributed in schools and hospitals during daytime but more concentrated in residential areas at night. The overall population density is higher for residential land at night than for other types of land during daytime. Residential land is distributed in both the central and outer areas. The difference in the quantity, density, and spatial distribution of the population between day and night explains this change in the major sensitive factors. 
Table 6. Statistics of blocks sensitive to target influencing factors at night.

\begin{tabular}{ccc}
\hline Target Influencing Factors & $\begin{array}{c}\text { Number of Blocks Most Sensitive to } \\
\text { Target Impact Factors }\end{array}$ & $\begin{array}{c}\text { Number of Blocks Sensitive to } \\
\text { Target Influencing Factors }\end{array}$ \\
\hline Population density & 131 & 259 \\
Proportion of elderly & 32 & 58 \\
Proportion of infants & 18 & 42 \\
Proportion of unemployed & 15 & 59 \\
Proportion of females & 10 & 77 \\
Proportion of middle school students & 9 & 64 \\
Proportion of hospital patients & 8 & 12 \\
Proportion of floating population & 1 & 35 \\
Proportion of population with & 1 & 33 \\
education level below junior high school & 0 & 19 \\
Proportion of kindergarten students & 0 & 21 \\
Proportion of primary school students & & \\
\hline
\end{tabular}

The numbers of blocks sensitive to the proportion of floating population or people with education level below junior school are significantly lower at night than during daytime. This is mainly due to the difference in distribution between daytime work space and nighttime living space. In addition, the vulnerable populations of the elderly and infants are distributed in the same space at night but have different distributions during daytime; consequently, some blocks are less sensitive to these two factors.

As shown in Figure 8, the blocks that are sensitive to the elderly proportion differ at night compared to daytime. At night, these blocks are concentrated in Zizhuyuan Jiedao, Balizhuang Jiedao, Ganjiakou Jiedao, Huayuanlu Jiedao, and Ginglongqiao Jiedao. Meanwhile, the blocks most sensitive to the elderly proportion are concentrated in Huayuanlu Jiedao, Zizhuyuan Jiedao, Balizhuang Jiedao, and Wanshoulu Jiedao, which is largely consistent with the equivalent daytime distribution because the elderly are mainly concentrated in residential areas during both daytime and nighttime.

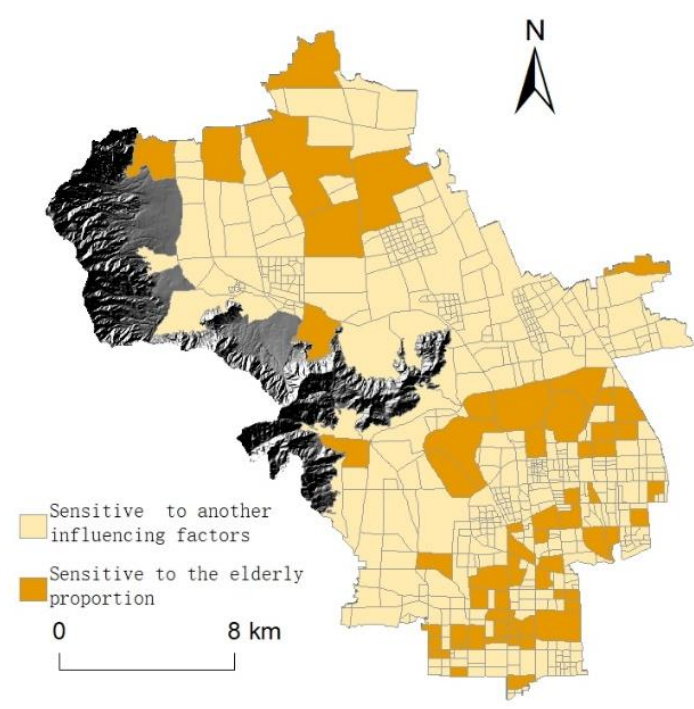

(a)

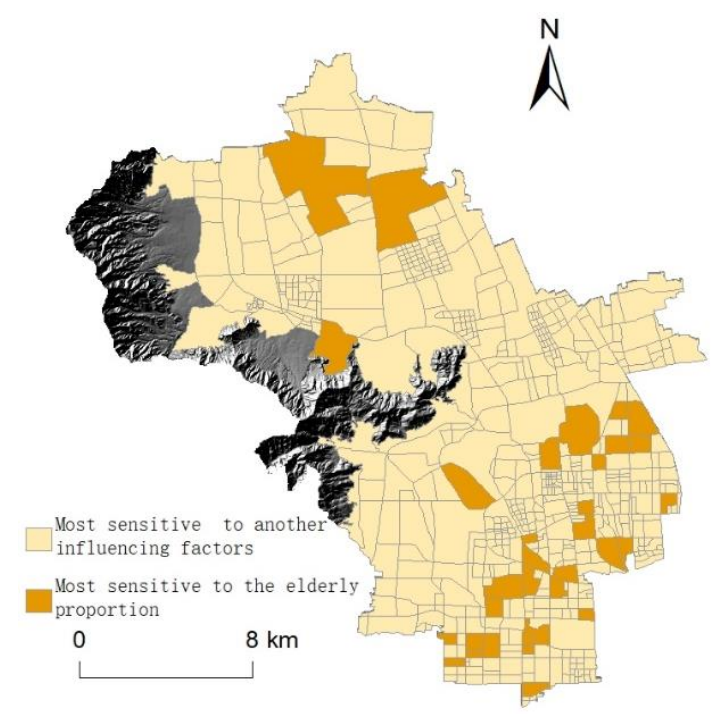

(b)

Figure 8. (a) Blocks sensitive to the elderly proportion at night; (b) Blocks most sensitive to the elderly proportion at night.

As shown in Figure 9, the blocks that are most sensitive to population density at night are concentrated in Huayuanlu Jiedao, Shuguang Jiedao, Zhongguancun Jiedao, Xisanqi Jiedao, Haidian Jiedao, Yangfangdian Jiedao, and Qinghe Jiedao. Both Xisanqi Jiedao and Qinghe Jiedao are at the urban-rural fringe and have a high floating population. Therefore, more attention should be paid to reducing population vulnerability in these areas. The blocks that are most sensitive to population 
density are more dispersed at night than during daytime because residential areas are scattered in the central and peripheral areas.

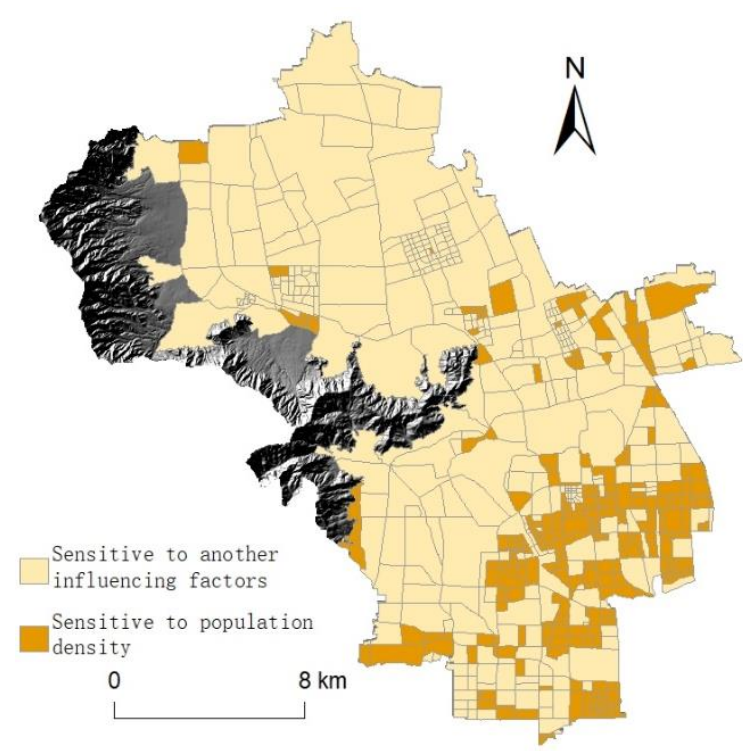

(a)

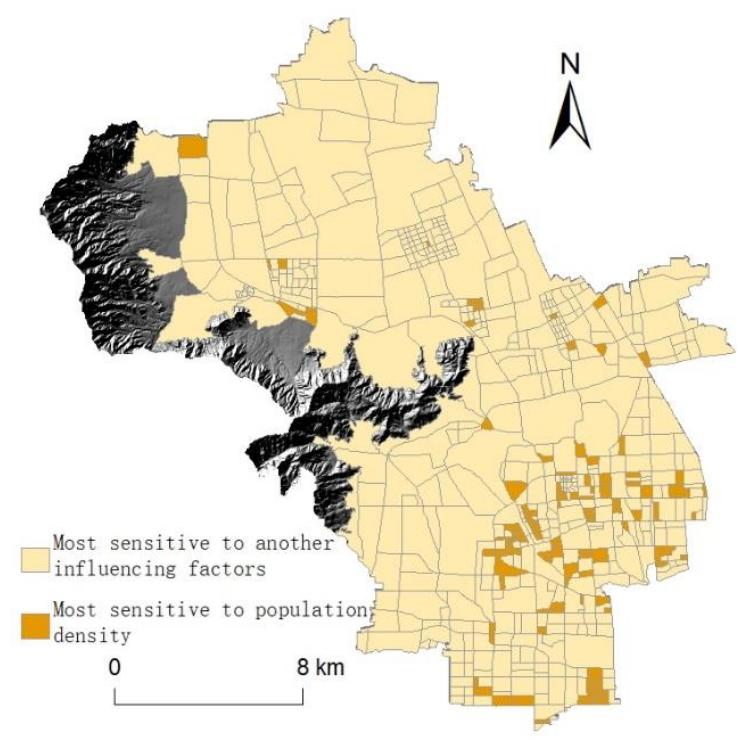

(b)

Figure 9. (a) Blocks sensitive to population density at night; (b) Blocks most sensitive to population density at night.

\subsection{Policy Implications}

In general, population vulnerability is high in Haidian District. There are different reasons for high population vulnerability in the district's various areas and the most vulnerable areas also vary between daytime and nighttime. The sensitivity analysis of population vulnerability reveals that the key influencing factors during daytime are population density and the proportion of the floating population, females, the elderly, and people with an education level below junior high school. Somewhat consistently, the key influencing factors at night are population density and the proportion of the elderly, females, students, and infants. Given the variation in factors affecting the vulnerability of residents in different blocks, the government should implement measures to reduce population vulnerability according to key influencing factors, day and night differences, and regional differences. For example, improving publicity and training on earthquake relief in regions with high numbers of poorly educated people and with a high population density would enhance residents' ability to avoid risk and cope with a disaster. Other measures could include: maintaining well-functioning evacuation routes and providing adequate shelters in areas with high population density; conducting a series of emergency drills and training sessions targeting vulnerable populations (such as women and the elderly) in areas where they are concentrated; targeted training for young adults living with elderly people or infants; and enhancing emergency education and training for students and teachers.

\section{Discussion and Conclusions}

By establishing a population spatialization model and a population vulnerability assessment model, and then performing sensitivity analysis, this paper provides a fine-scale analysis of populations' vulnerability to disaster. This study makes two key contributions. First, it refines the social vulnerability assessment models developed in previous studies. To effectively identify spatiotemporal differences in the distribution of population vulnerability, so as to better inform the planning and implementation of disaster prevention and mitigation measures, we took blocks as the basic unit of analysis. Based on differences in spatial population distribution between daytime and nighttime, a refined population 
spatialization model was used, providing a feasible method for obtaining fine-scale population data. Our proposed approach supplements the static administrative-area-level analysis of population vulnerability in China. Second, we offer further insight into assessment content by assessing three aspects of population vulnerability: the natural, socioeconomic, and spatial attributes of a population. Focusing on vulnerable populations, we identify the key influencing factors of population vulnerability through sensitivity analysis. This method delves deeper into demographic characteristics than previous analyses of social vulnerability that focus on macroeconomic characteristics.

Using the above methods of analysis, this paper estimates the number of vulnerable populations and the population vulnerability at block scale during daytime and nighttime. It identifies blocks with high population vulnerability by day and by night and identifies the (most) important factors influencing population vulnerability. In general, population vulnerability in Haidian District is high, with reasons varying in different areas and differences between daytime and nighttime. The government should implement remedial measures that correspond with the key influencing factors, day and night differences, and regional differences. Compared with the results of population (social) vulnerability analyses at the administrative district scale (minimum scale is township and street) and $1 \mathrm{~km}$ grid, this study provides a more practical and effective starting point for reducing population vulnerability and implementing disaster prevention and mitigation measures, which is of practical significance for China given its high frequency of earthquakes.

Our population spatialization model has several limitations and needs to be further refined. This study simplified population distribution by using an indoor pattern, without considering the distribution of people outside, such as outdoor workers and those commuting or in open spaces. During weekday peak hours from 07:30-09:00 and 17:00-19:00, there are many commuters using public transportation in Beijing. Therefore, future models should describe the population trajectory in more detail and divide the working day into more time periods.

To estimate vulnerable populations and population density at block level, our model assumed that the building area per capita was the same for vulnerable populations on the same type of land. Although we considered detailed land-use and building data, these both differ from actual conditions. Besides the number of building floors, the grade of a residential area also influences population density in China. For example, the building area per capita in a high-grade residential area might be much higher than that in a low-grade residential area. In places with a larger floating population, the building area per capita is typically smaller. Therefore, the model's parameters should be further optimized based on other characteristics, such as house price or house type, thereby recognizing the difference in building area per capita between council houses and commercial houses.

Finally, the indicators selected in this paper are relatively limited, and mainly focus on vulnerable populations. Further study should include more economic elements and collect related data to expand the indicator system for population vulnerability at a fine scale.

Please see the Supplementary Materials.

Supplementary Materials: The following are available online at http:/ /www.mdpi.com/2071-1050/11/7/2149/ s1.

Author Contributions: Conceptualization, H.Y. and X.G.; methodology, H.Y. and W.Q.; validation, H.Y., X.G. and W.Q.; formal analysis, H.Y.; investigation, H.Y.; resources, H.Y.; writing-original draft preparation, H.Y. and X.G.; writing-review and editing, H.Y. and X.G.; visualization, H.Y.; funding acquisition, H.Y.

Funding: This work was funded by the Key Research Base of Philosophy and the Social Sciences of Zhejiang Province (Grant number: 16JDGH041); the MOE (Ministry of Education in China) Project of Humanities and Social Sciences (Grant number: 17YJCZH234) and the K.C. Wong Magna Fundof Ningbo University.

Conflicts of Interest: The authors declare no conflict of interest. 


\section{References}

1. Zhao, B.; Taucer, F.; Rossetto, T. Field investigation on the performance of building structures during the 12 May 2008 Wenchuan earthquake in China. Eng. Struct. 2009, 31, 1707-1723. [CrossRef]

2. Wen, J.H.; Yan, J.P.; Yin, Z.E.; Meng, Q.J.; Yie, X.L. Mainstreaming disaster risk management in China. Prog. Geogr. 2010, 29, 771-777.

3. Yuan, H.; Niu, F.; Gao, X. A study on urban economic vulnerability evaluation system. J. Geogr. Sci. 2015, 25, 1264-1278. [CrossRef]

4. Shi, P.J.; Du, J.; Ji, M.X.; Liu, J.; Wang, J.A. Urban risk assessment research of major natural disasters in China. Adv. Earth Sci. 2006, 21, 170-177.

5. Jiang, F.R.; Jiang, B. Impact of super thunderstorm on 21 July in Beijing and countermeasures. China Water Resour. 2012, 15, 19-22.

6. Xu, W.; Wang, J.A.; Shi, P.J.; Zhou, J.H. Hazard degree assessment of urban earthquake disaster in China. J. Nat. Disasters 2004, 13, 9-15.

7. Xu, W.; Liu, J.F.; Xu, G.D.; Wang, Y.; Liu, L.Y.; Shi, P.J. Earthquake disasters in China. In Natural Disasters in China; Shi, P.J., Ed.; Springer: Berlin, Germany, 2016; pp. 37-72.

8. Gao, X.L.; Yuan, H.H.; Qi, W.; Liu, S. Assessing the social and economic vulnerability of urban areas to disasters: A case study in Beijing, China. Int. Rev. Spat. Plan. Sustain. Dev. 2014, 2, 42-62. [CrossRef]

9. Giovene di Girasole, E.; Cannatella, D. Social vulnerability to natural hazards in urban systems. An application in Santo Domingo (Dominican Republic). Sustainability 2017, 9, 2043. [CrossRef]

10. Willis, I.; Fitton, J.A. Review of multivariate social vulnerability methodologies: A case study of the River Parrett catchment, UK. Nat. Hazard Earth Sys. Sci. 2016, 16, 1387. [CrossRef]

11. Fatemi, F.; Ardalan, A.; Aguirre, B.; Mansouri, N.; Mohammadfam, I. Social vulnerability indicators in disasters: Findings from a systematic review. Int. J. Disaster Risk Reduct. 2017, 22, 219-227. [CrossRef]

12. Armaş, I.; Toma-Danila, D.; Ionescu, R.; Gavriş, A. Vulnerability to earthquake hazard: Bucharest case study, Romania. Int. J. Disaster Risk Sci. 2017, 8, 182-195. [CrossRef]

13. Lee, Y.J. Social vulnerability indicators as a sustainable planning tool. Environ. Impact Assess. Rev. 2014, 44, 31-42. [CrossRef]

14. Adger, W.N.; Brooks, N.; Bentham, G.; Agnew, M.; Eriksen, S. New Indicators of Vulnerability and Adaptive Capacity; Tyndall Centre for Climate Change Research: Norwich, UK, 2004.

15. Cerchiello, V.; Ceresa, P.; Monteiro, R.; Komendantova, N. Assessment of social vulnerability to seismic hazard in Nablus, Palestine. Int. J. Disaster Risk Reduct. 2018, 28, 491-506. [CrossRef]

16. Pollnac, R.B.; Seara, T.; Colburn, L.L.; Jepson, M. Taxonomy of USA east coast fishing communities in terms of social vulnerability and resilience. Environ. Impact Assess. Rev. 2015, 55, 136-143. [CrossRef]

17. Nelson, K.S.; Abkowitz, M.D.; Camp, J.V. A method for creating high resolution maps of social vulnerability in the context of environmental hazards. Appl. Geogr. 2015, 63, 89-100. [CrossRef]

18. Wood, N.J.; Burton, C.G.; Cutter, S.L. Community variations in social vulnerability to Cascadia-related tsunamis in the US Pacific Northwest. Nat. Hazards 2010, 52, 369-389. [CrossRef]

19. Antwi-Agyei, P.; Dougill, A.J.; Fraser, E.D.G.; Stringer, L.C. Characterising the nature of household vulnerability to climate variability: Empirical evidence from two regions of Ghana. Environ. Dev. Sustain. 2013, 15, 903-926. [CrossRef]

20. Dwyer, A.; Zoppou, C.; Nielsen, O.; Day, S.; Roberts, S. Quantifying Social Vulnerability: A Methodology for Identifying Those at Risk to Natural Hazards; Geoscience Australia: Canberra, Australia, 2004.

21. Huynh, L.T.M.; Stringer, L.C. Multi-scale assessment of social vulnerability to climate change: An empirical study in coastal Vietnam. Clim. Risk Manag. 2018, 20, 165-180. [CrossRef]

22. Wenxiu, D.; Xiaoli, L.; Zhiqiang, L.; Aixia, D.; Yimei, Z.; Qile, T. Population and housing grid spatialization in Yunnan Province based on grid sampling and application of rapid earthquake loss assessment: The Jinggu Ms6.6 earthquake. Geod. Geodyn. 2014, 5, 25-33. [CrossRef]

23. Xu, J.; An, J.; Nie, G. A quick earthquake disaster loss assessment method supported by dasymetric data for emergency response in China. Nat. Hazards Earth Syst. Sci. 2016, 16, 885-899. [CrossRef]

24. Zhang, Y.; Lindell, M.K.; Prater, C.S. Vulnerability of community businesses to environmental disasters. Disasters 2009, 33, 38-57. [CrossRef] 
25. Shi, Y. Population vulnerability assessment based on scenario simulation of rainstorm-induced waterlogging: A case study of Xuhui District, Shanghai City. Nat. Hazards 2013, 66, 1189-1203. [CrossRef]

26. Chen, L.; Xu, W.; Zhou, X.; Ma, Y.L.; Yuan, Y.; Qian, X.; Ge, Y. Assessment of social vulnerability to natural disasters of cities: A case study of Shanghai city. J. Catastrophol. 2012, 27, 98-100.

27. Chengjing, N.; Linsheng, Y.; Hairong, L. Macro assessment of seismic population vulnerability in China. Prog. Geogr. 2012, 31, 375-382.

28. He, S.; Yang, S.; Wang, W.P.; Shi, M.M. Spatial-temporal evolution of social vulnerability to natural hazards in China. J. Beijing Normal Univ. (Nat. Sci.) 2015, 51, 299-305.

29. Honghuan, G. Community Based Assessment of Social Vulnerability to Natural Hazards in Shanghai; Shanghai Normal University: Shanghai, China, 2016.

30. Qian, Z. Herders' social vulnerability to climate change: A case of desert grassland in Inner Mongolia. Sociol. Stud. 2011, 6, 171-245.

31. Aubrecht, C.; Freire, S.; Neuhold, C.; Curtis, A.; Steinnocher, K. Introducing a temporal component in spatial vulnerability analysis. Disaster Adv. 2012, 5, 48-53.

32. Alaghi, K. Asset and systematic risk. Afr. J. Bus. Manag. 2012, 6, 3504-3509.

33. Cutter, S.L.; Boruff, B.J.; Shirley, W.L. Social vulnerability to environmental hazards. Soc. Sci. Q. 2003, 84, 242-261. [CrossRef]

34. Cardona, O.D. Indicators of Disaster Risk and Risk Management: Program for Latin America and the Caribbean: Summary Report; Inter-American Development Bank: Washington, DC, USA, 2005.

35. Esty, D.; Levy, M.; Srebotnjak, T.; De Sherbinin, A. Environmental Sustainability Index; Yale Center for Environmental Law and Policy: New Haven, CT, USA, 2005.

36. United Nations Development Programme. The Real Wealth of Nations: Pathways to Human Development; United Nations Development Programme: New York, NY, USA, 2010.

37. Tate, E. Social vulnerability indices: A comparative assessment using uncertainty and sensitivity analysis. Nat. Hazards 2012, 63, 325-347. [CrossRef]

38. Long, Y.; Shen, Y.; Jin, X. Mapping block-level urban areas for all Chinese cities. Ann. Am. Assoc. Geogr. 2016, 106, 96-113. [CrossRef]

39. Wieland, M.; Pittore, M.; Parolai, S.; Zschau, J.; Moldobekov, B.; Begaliev, U. Estimating building inventory for rapid seismic vulnerability assessment: Towards an integrated approach based on multi-source imaging. Soil Dyn. Earthq. Eng. 2012, 36, 70-83. [CrossRef]

40. Cheng, J.; Turkstra, J.; Peng, M.; Du, N.; Ho, P. Urban land administration and planning in China: Opportunities and constraints of spatial data models. Land Use Policy 2006, 23, 604-616. [CrossRef]

41. Jaiswal, K.; Wald, D.; Porter, K. A global building inventory for earthquake loss estimation and risk management. Earthq. Spectra 2010, 26, 731-748. [CrossRef]

42. Cutter, S.L.; Emrich, C.T.; Webb, J.J.; Morath, D. Social Vulnerability to Climate Variability Hazards: A Review of the Literature. Final report to Oxfam America. 2009. Available online: http:/ / adapt.oxfamamerica.org/ resources/Literature_Review.pdf (accessed on 20 March 2019).

43. Zhang, W.; Xu, X.; Chen, X. Social vulnerability assessment of earthquake disaster based on the catastrophe progression method: A Sichuan Province case study. Int. J. Disaster Risk Reduct. 2017, 24, 361-372. [CrossRef]

44. Maharani, Y.N.; Lee, S.; Ki, S.J. Social vulnerability at a local level around the Merapi volcano. Int. J. Disaster Risk Reduct. 2016, 20, 63-77. [CrossRef]

45. Wang, F.; Jiang, J.Q. Discussion on the comprehensive vulnerability analysis method of urban earthquake disasters. J. Seismol. Res. 2005, 28, 95-101.

46. Su, G.W.; Zhu, L.; Ma, Z.J.; Qi, W.H.; Zhen, Y.; Li, M. Preliminary study on macro-vulnerability changes in earthquake disaster areas in Beijing-Tianjin-Tangshan Region: Spatial change. Seismol. Geol. 2007, 29, $25-33$.

47. Jie, Z.; Huiying, G.; Qi, L. Research on prediction model of earthquake casualties based on Wenchuan Earthquake. China Saf. Sci. J. 2011, 21, 59-64.

48. Zhang, N.; Huang, H.; Su, B.; Zhang, H. Population evacuation analysis: Considering dynamic population vulnerability distribution and disaster information dissemination. Nat. Hazards 2013, 69, 1629-1646. [CrossRef]

49. Zhang, N.; Huang, H. Social vulnerability for public safety: A case study of Beijing, China. Chin.Sci. Bull. 2013, 58, 2387-2394. 
50. Hu, L.; He, Z.; Liu, J. Adaptive multi-scale population spatialization model constrained by multiple factors: A case study of Russia. Cartogr. J. 2017, 54, 265-282. [CrossRef]

51. Su, M.D.; Lin, M.C.; Hsieh, H.I.; Tsai, B.W.; Lin, C.H. Multi-layer multi-class dasymetric mapping to estimate population distribution. Sci. Total Environ. 2010, 408, 4807-4816. [CrossRef]

52. Jia, P.; Qiu, Y.; Gaughan, A.E. A fine-scale spatial population distribution on the high-resolution gridded population surface and application in Alachua County, Florida. Appl. Geogr. 2014, 50, 99-107. [CrossRef]

53. Gallego, F.J. A population density grid of the European Union. Popul. Environ. 2010, 31, 460-473. [CrossRef]

54. Dong, N.; Yang, X.; Cai, H. Research progress and perspective on the spatialization of population data. J. Geo-Inf. Sci. 2016, 18, 1295-1304.

55. Maantay, J.A.; Maroko, A.R.; Herrmann, C. Mapping population distribution in the urban environment: The cadastral-based expert dasymetric system (CEDS). Cartogr. Geog. Inf. Sci. 2007, 34, 77-102. [CrossRef]

56. Silvan-Cardenas, J.L.; Wang, L.; Rogerson, P.; Wu, C.; Feng, T.; Kamphaus, B.D. Assessing fine-spatial-resolution remote sensing for small-area population estimation. Intern. J. Remote Sens. 2010, 31, 5605-5634. [CrossRef]

57. Lwin, K.K.; Murayama, Y. A GIS Approach to Estimation of Building Population for Micro-spatial Analysis. Trans. GIS 2009, 13, 401-414. [CrossRef]

58. Openshaw, S. Learning to live with errors in spatial databases. In Accuracy of Spatial Databases; Good-Child, M.F., Gopal, S., Eds.; Taylor \& Francis: London, UK, 1989; pp. 263-276.

59. Huang, R.Q. Urban structure of Beijing. Chin. J. Popul. Sci. 2003, 5, 49-55.

60. Ramli, M.W.A.; Alias, N.E.; Taib, S.M. Evaluating Transportation Modes and Routes for Disaster Relief in Kelantan Using Geographical Information System. In Improving Flood Management, Prediction and Monitoring: Case Studies in Asia; Emerald Publishing Limited: Bingley, UK, 2018; pp. 63-71.

61. Masuya, A.; Dewan, A.; Corner, R.J. Population evacuation: Evaluating spatial distribution of flood shelters and vulnerable residential units in Dhaka with geographic information systems. Nat. Hazards 2015, 78, 1859-1882. [CrossRef] 